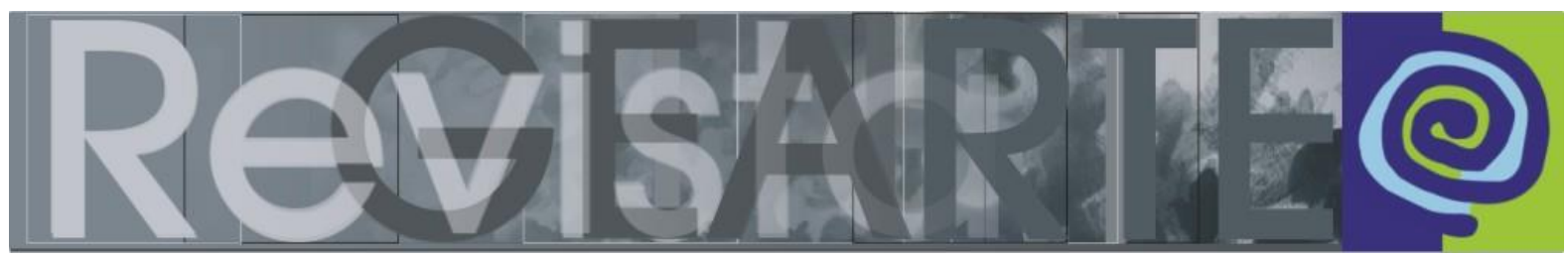

e-ISSN 2357-9854

\title{
Arte contemporânea e cultura visual: desdobramentos da natureza-morta no ensino das artes visuais
}

\author{
Lutiere Dalla Valle (Universidade Federal de Santa Maria - UFSM, \\ Santa Maria/RS, Brasil) \\ Milena Regina Duarte Corrêa (Universidade Federal de Santa Maria - UFSM, \\ Santa Maria/RS, Brasil)
}

\begin{abstract}
RESUMO - Arte contemporânea e cultura visual: desdobramentos da natureza-morta no ensino das artes visuais - A partir da natureza-morta, este texto examina a articulação entre arte contemporânea e cultura visual no ensino das artes visuais. A escrita toma como via de experimentação relatos da experiência docente vivenciadas em escola da rede pública ao desenvolver práticas educativas relacionando produções tradicionais, modernas e atuais no que tange às distintas formas de abordar o tema ao longo das últimas décadas. Neste sentido, com base nas perspectivas de Moxey, Hernández e Mitchell acerca das múltiplas - não lineares - alternativas de aproximação com os campos da história da arte e demais campos disciplinares (linguística, estudos visuais, estudos culturais) propõe-se alguns aspectos relevantes para o desenvolvimento de ações educativas nos mais variados contextos de ensino. Além disso, discorremos acerca das significativas contribuições da perspectiva educativa da cultura visual para explorar a potencia subjetiva entorno às contingências históricas e sociais que configuram o olhar.
\end{abstract}

PALAVRAS-CHAVE

Arte contemporânea. Cultura visual. Natureza-morta. Ensino das artes visuais.

RESUMEN - Arte contemporáneo y cultura visual: desdoblamientos de la naturaleza muerta en la educación artística - A partir de la naturaleza-muerta, este texto examina la articulación entre el arte contemporáneo y la cultura visual en la educación artística. La escritura toma como vía de experimentación los relatos de experiencia docente vivenciadas en la escuela de la red pública al desarrollar prácticas educativas relacionando producciones tradicionales, modernas y actuales en lo que se refiere a las distintas formas de abordar el tema en las últimas décadas. En este sentido, con base en las perspectivas de Moxey, Hernández y Mitchell acerca de las múltiples - no lineales alternativas de aproximación con los campos de la historia del arte y demás campos disciplinares (lingüística, estudios visuales, estudios culturales) se proponen algunos aspectos relevantes para el desarrollo de acciones educativas en los más variados contextos de la enseñanza. Además, acerca de las significativas contribuciones de la perspectiva educativa de la cultura visual para explorar la potencia subjetiva en torno a las contingencias históricas y sociales que configuran la mirada.

PALABRAS CLAVE

Arte contemporáneo. Cultura visual. Naturalezas-muerta. Educación artística.

\section{Introdução}

Partindo da recorrência da natureza-morta no campo artístico, impulsionamonos a pensar sua potencialidade no ensino das artes visuais por sua vasta gama de contingências que aparecem em todos os períodos históricos. Relacionando às

VALLE, Lutiere Dalla; CORRÊA, Milena Regina Duarte. Arte contemporânea e cultura visual: 428 desdobramentos da natureza-morta no ensino das artes visuais.

Revista GEARTE, Porto Alegre, v. 4, n. 3, p. 428-439, set./dez. 2017.

Disponível em: http://seer.ufrgs.br/gearte 
categorias idealizadas pela historicidade (calcada sobretudo em estilos), o interesse, nesta escrita, é repensá-la sob o viés da multiplicidade, das probabilidades: não linear, que possa ultrapassar a simples narrativa cronológica para torna-la aberta aos possíveis desdobramentos (MOXEY, 2003). Nesta via, a história cronológica pode ser repensada a partir da cultura visual, perspectiva que estimula as micronarrativas, incita o inusitado, caminhos que ainda não tenham sido transitados. Ou seja, não exclui os múltiplos significados, pelo contrário, estimula que os relatos invisíveis sejam recuperados diante da supremacia eurocêntrica, branca e patriarcal que por muitos séculos legitimou a cronologia das belas artes, selecionando obras e descartando outras.

Neste sentido, ao examinar a compreensão que detemos em relação aos artefatos visuais (que definem nossas formas de ver e estabelecer relações cognitivas) nos implica reconhecer que cada contexto cultural, cada tradição reclama para si determinadas visões e entendimentos a respeito do mundo. Portanto, ao fazermos uso da perspectiva da cultura visual para explorar o campo visual e seus desdobramentos no campo das imagens oriundas da história da arte (neste caso, atreladas ao tema da natureza-morta), é possível promover diálogos significativos ao examinar experiências próprias provocadas a partir do olhar subjetivo.

Deste modo, compreendemos que ver não consiste em uma ação individual apenas, mas caracteriza-se, sobretudo, por uma prática social contingente: nossas referências culturais e imagéticas não são absolutamente nossas, uma vez que estão atreladas às comunidades discursivas às quais nos vemos implicados. Ao relacionar imagens retiradas de seus contextos de produção, circulação e legitimação, necessitamos, portanto, examinar nossas concepções sobre o que consideramos e o que descartamos. Quando articulamos junto às obras as nossas experiências, nos aproximamos de processos que exploram visões e repertórios conceituais ao mobilizar percepções variadas a partir da prática de estabelecer relações. Como um rizoma, estes processos oriundos da experiência vivida acenam caminhos que se utilizam da reflexividade inventiva como recurso para compreender onde nos situamos e quais são as lentes culturais que usamos, não apenas para visualizar, mas também para pensar os entremeios que são invisibilizados. 


\section{Gênero que perdura e se propaga: delimitando o campo de estudo}

Desde o momento em que foi assumida como gênero da pintura, a naturezamorta produziu ao longo dos séculos, uma série de possibilidades e interpretações. Com base em Canton, a partir de uma perspectiva de história da arte linear, seu conceito descenda da palavra holandesa Stilleven, em inglês Still life que se refere a uma natureza parada, inerte, composta de objetos e/ou seres inanimados (CANTON, 2004). Para a autora, inicialmente, a temática não tinha preocupação em contar uma história, indagar ou questionar ideias, pois os artistas que as estudavam, estariam interessados nos próprios objetos representados: cor, textura, volume, superfície e a relação entre eles (característica que perdura em muitos casos), mesmo que o gênero tenha sofrido inúmeras transformações em termos de elaboração visual e/ou conceitual. Uma das referências que mais aparecem quando se fala em naturezamorta e composição é Paul Cézanne (1839-1906). Seu estudo de luz e sombra e a preocupação com os valores estéticos e compositivos, revolucionou a arte do seu tempo e de seus contemporâneos.

Mudanças significativas se sucederam durante períodos como o modernismo e suas vanguardas. $O$ estudo dos objetos fragmentados e distorcidos caracterizaram os trabalhos de Pablo Picasso (1881-1973) outro revolucionário que rompeu com a arte naturalista de seu tempo, em valor da exploração de uma nova natureza-morta. Por esse motivo, mediante a infinidade de aproximações e desdobramentos, a naturezamorta tem se mostrado um tema que nunca desapareceu dos olhares atentos dos artistas: renovam-se os olhares, as perspectivas e os enfoques narrativos. $\mathrm{Na}$ contemporaneidade, percebemos sua proliferação com requinte em suas várias manifestações: passando das relações de contemplação ao estranhamento, aos desmantelamentos das noções de estrutura, próprias do pensamento moderno (ROSE apud GALLEGHER, 2004).

De acordo com Canton:

A natureza morta é, afinal, um gênero que dialoga com a história da arte ocidental e os sistemas estéticos de forma abrangente. $\mathrm{Na}$ arte contemporânea, o conceito de natureza-morta perpetua-se, expandindo-se numa proliferação de suportes e maneiras de lidar com sua forma, sentido, altitude (CANTON, 2004, p. 12). 
Neste sentido, a natureza-morta na contemporaneidade implica distintas relações de sua materialidade entorno ao 'espectador', uma vez que ultrapassa a "intenção" do artista, para manifestar-se por meio de apropriações, proposições essencialmente conceituais, difundidas em múltiplos espaços, envolvendo elementos oriundos do cotidiano. Há pinturas de naturezas-mortas, por exemplo, que assumem um aspecto mais experimental, sendo compostas por objetos e composições simples - como por exemplo, a obra de Jason deCaires Taylor: uma construção submersa no oceano que estabelece uma relação completamente inusitada, uma vez que temos acesso apenas por registros fotográficos ou audiovisuais (Figura 1).

Figura 1 - Jason de Caires Taylor: the last supper Mexico growth

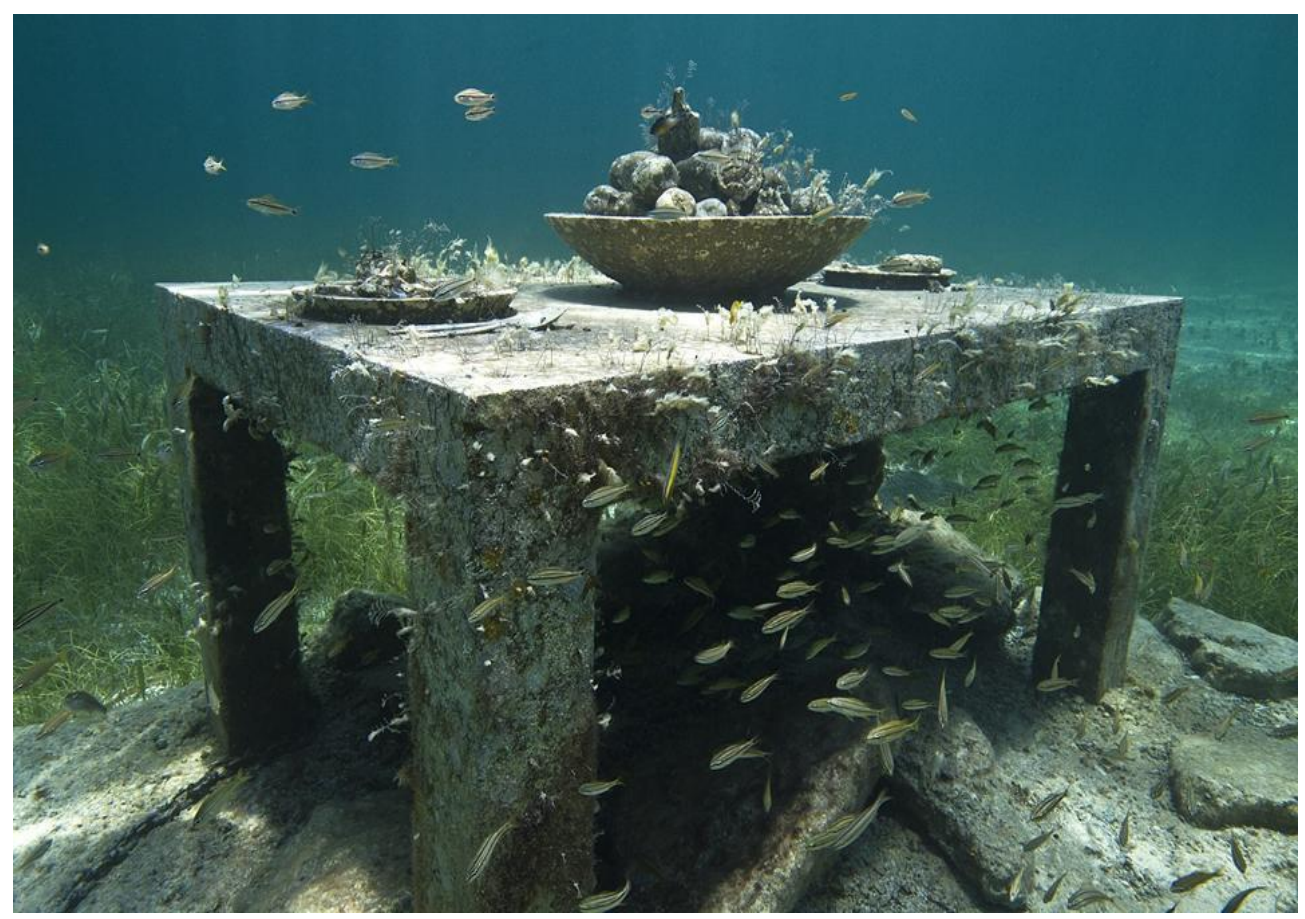

Fonte: <http://www.underwatersculpture.com/?doing_wp_cron= 1499917827.7942280769348144531250 >. Acesso em 12/07/2017.

A partir deste exemplo, podemos argumentar que a relação com os artefatos visuais é também complexa, divergente, por vezes provocadora, contrapondo-se ao imaginário do pintor do século XIX que propunha certo distanciamento de suas composições (completamente controladas) e representadas a partir da inércia.

Já Andy Warhol reproduziu, incessantemente, a imagem de Campbell's saturando a representação de alguns objetos, adotando (em alguns casos) alguns dos 
princípios da natureza-morta: cotidianidade, popularidade das imagens, atreladas à efervescência visual. Apropriadas, podiam ser empregadas diretamente ao campo artístico, redefinindo os valores e significados atribuídos usualmente aos objetos.

Examinar essa história da natureza-morta de maneira relativista, interpretativa e circunstancial, nos permite autorizar-nos experimentar conexões dialógicas, a pensar a partir de outras perspectivas de cunho relacional, fragmentário e narrativo (MOXEY, 2001). Por esse motivo, o projeto pensado para o ensino de artes visuais na escola buscou contemplar a variedade de produções e interpretações possíveis a partir do tema da natureza-morta, do moderno à contemporaneidade.

\section{Experiências educativas}

Nosso ponto de partida para desenvolver projetos educativos na escola, com um grupo de adolescentes, foi partir da negociação a partir de seus conhecimentos prévios, conexões com experiências visuais cotidianas, imagens de interesse, buscando estabelecer algum tipo de vínculo conceitual/vivencial. Foram também as inquietações acerca das relações com a história da arte (conteúdo estipulado pela escola) frente aos desafios de dialogar com as suas experiências, já que a perspectiva da cultura visual interessa-se pelas experiências cotidianas e suas relações de afeto que reverberam produções de sentido e significação (DIAS, 2011).

Entre conversas, provocações, fotos, revistas e recortes, a seleção de imagens para o que se podia denominar "natureza-morta" foi tão interessante quanto a composição em colagem formando um mapa visual desses dois artefatos: Móveis são natureza-morta? Maçã não pode ser natureza-morta porque não comemos fruta morta! O objetivo era que as produções se inter-relacionassem, que as palavras não descrevessem as imagens e essas imagens tivessem força sozinhas. Novamente, a produção visual mostrou as múltiplas possibilidades que a natureza-morta ganha, se pensada por diferentes enfoques e abordagens. O que dialoga com a abordagem da cultura visual em estimular proposições imaginativas entre produção de imagens e artefatos que antes não tinham alguma relação (MOXEY, 2001). Durante a atividade em sala de aula, diversos atravessamentos entre as imagens aconteceram: os objetivos da contemporaneidade em criticar ou indagar certas ações, a necessidade 
de conceitos atrelados às obras de arte, as dúvidas entorno às "pretensões" da arte contemporânea diante de seus "enigmas". As palavras "natureza-morta" corporificadas no quadro negro foram o começo de nossas elaborações. Em um jogo de palavras e imagens, houve problematização, busca por diferentes abordagens da natureza-morta em distintos períodos históricos. Desde a composição cubista e geométrica de Fruteira e pão sobre uma mesa (1909) de Picasso, atravessando as composições de estudo de cor em Maçãs e laranjas (1895-1990) de Cézanne, em contraste com a comercialização de Campbell's Soup Cans (1962) de Andy Warhol e, Pets (2008) de Eduardo Srur indagando questões sociais/ambientais. Diálogo entre "sequelas" e "decomposição", entre "apodrecimento" e "devastação".

No que diz respeito às pinturas modernas e impressionistas, por exemplo, pensamos nas proximidades e distanciamentos que podem ser lançadas entre elas: 0 objetivo naturalista de representar os objetos repudiados pela noção de desconstrução na modernidade através de Braque (1882-1963) e o quanto contribuiu para as demais desconstruções de formas, cores e volumes em seus contemporâneos. Enfim, múltiplas imagens da história da arte e das produções contemporâneas foram revistas sob o olhar atento dos estudantes, possibilitando conexões entre suas experiências e abordagens históricas da arte, endossando que a maneira e os aspectos de como olhamos é particularmente relevante para a construção do nosso conhecimento (DIAS, 2011).

Durante a finalização das atividades, o objetivo foi pensar e produzir apropriações de naturezas-mortas, podendo serem utilizadas composições do espaço escolar, composições a partir de fotografias, das imagens da produção de artistas, ou, o que pudessem dialogar com as ideias desenvolvidas durante as aulas. A apropriação implicaria uma nova e singular interpretação, transformando aquele objeto comum em uma outra significação, atingindo um estágio seguinte ao da representação utilitária apenas, mas impulsionando o âmbito da subjetivação. Segundo Cherem (2009, p. 152-155) trata-se da ação de recombinar elementos e artefatos em um "desvio", e que carregará em si novas comparações, agrupamentos e classificações, ampliando combinações e explorando novos ângulos, fragmentos, isolando e recombinando detalhes. Desse modo, aquelas apropriações se 
configuraram como possibilidades inventivas ao contribuir para pensar caminhos que o ensino das artes visuais atravessa, operando com questões do tempo presente.

Os questionamentos e apontamentos geraram problematizações acerca de revisões históricas, em particular, da natureza-morta sendo esmiuçada à luz das ideias da cultura visual. Uma rememoração daquelas imagens a partir de outras ideias, já que para fazer parte deste composto, as imagens poderiam passar por redefinição ou mudanças através de experimentações. Abrindo assim, um campo de possibilidades e abrangentes estratégias didático-pedagógicas para o ensino das artes visuais na educação básica.

\section{A história da arte revisitada pelas vias da cultura visual}

Pensar as imagens e atribuir significados à elas envolvem valores e práticas culturais/sociais muito peculiares e relativas ao contexto de produção: requerem o exercício constante de revisão uma vez que podem mobilizar nossas formas de conceber o mundo e a nós mesmos.

Ao fazer uso "de uma história da arte revista", foi necessário reconhece-la como potência que se centra na produção de significados, assim como abre portas para a produção de conhecimento desde enfoques muito variados, onde não se busca consenso, mas desacordos de interpretação. Assim, o estudo das imagens envolve o reconhecimento de sua heterogeneidade, das diferentes circunstâncias de produção e da variedade de funções que lhes são atribuídas a partir das mais variadas perspectivas.

Entretanto, a partir da cultura visual, tomamos como via primeira o mundo das imagens, que expressam e definem nossas formas de pensar e viver, que vão além das categorias da história da arte tradicional - que já não podem ser estudadas com os mesmos conceitos e/ou critérios que antes eram utilizados. Por esse motivo, somos defensores do ensino de artes visuais a partir de uma história da arte não linear, não apenas ocidental e clássica, mas também oriental, latina, pelas lentes das mulheres, etc. 
Em sua escrita Nostalgia for the real, 2001, Moxey nos provoca a pensar a história da arte que temos proximidade: escrita em determinado local e cultura, atrelada à época de sua criação, a partir de uma perspectiva particular, por isso, não pode ser considerada universal. Entretanto, com os estudos de uma nova, ou várias histórias da arte, entende-se que na luta por um método central e unificador, foi substituída a história convincente por muitas histórias, que se relacionam entre si, de forma autônomas, ao encontro das reivindicações da arte contemporânea (MOXEY, 2001). Com todas as suas possibilidades, a história da arte não precisa de direções fixas, pois pode desenhar percursos multidisciplinares, de estranhamento, de discrepância, impulsionados mais pela movimentação do que pela perspectiva 'evolutiva' da arte. Ou seja, validadas por pequenos discursos e relatos que talvez não tenham sido contemplados anteriormente.

Logo, o colapso da ideia unificadora da história da arte, implica e mobiliza diferentes histórias, assim como a arte e o conhecimento, que não são fixos e nem permanentes. De fato, ao que se centra o estudo da cultura visual, uma abordagem que não pretende configurar-se como um campo disciplinar, mas pensar-se a partir da diferença, da multiplicidade cultural e, sobretudo, da fluidez. Tomar partido dos processos de subjetivação que podem ser proporcionados a partir do trabalho com imagens oriundas das visualidades contemporâneas, ao abordar a "subjetividade como a possibilidade de inventarmos a nós mesmos diante dos determinismos da identidade", isto é, ir além da identidade fixa para questionar os sistemas de pensamento hegemônico impregnados do sentimento de naturalização de verdades (HERNÁNDEZ, 2007).

Portanto, expandir as possibilidades de diálogo entre as experiências visuais cotidianas e suas conexões com os campos da historia da arte que contribuem para criação de objetos de desejo e de consumo, assim como problematizam as diversas situações e contextos que permeiam as relações de submissão e agenciamento que contornam a vida diária. Nas palavras de Paul Duncum

A cultura visual possui uma estrutura rizomática: carece de um núcleo e pode expandir-se infinitamente. Uma imagem está conectada a outra, que, por sua vez, está conectada a uma terceira; imagens associam-se à literatura, poemas, letras de canções e filosofias de vida. Assim como a internet - esta 
também um rizoma -, a cultura visual não detém um centro ou uma estrutura linear. [...] a cultura visual dissemina-se, por associação, de uma ideia, imagem, tópico, texto, etc., para outro. Uma coisa conduz a outra e mais outra. Assemelha-se mais à grama que à árvore (DUNCUM, 2011, p. 21).

Ainda para o autor, as imagens oriundas da cotidianidade como dispositivos do olhar crítico, reflexo de um determinado traço de uma problemática atual, se coloca como fator de aproximação, de problematização e de inquietação frente àquilo que é posto como imutável e intransponível - neste caso, às imagens de naturezas-mortas deslocadas da historia da arte.

Partindo da ideia de que tudo aquilo que vemos está impregnado de sentido, significados desde o contexto social e de relações de poder dentro de determinada cultura, as configurações de natureza-morta (nos variados contexto) podem ser entendidas levando em consideração um grande número de elementos culturais que abarcam também, questões biográficas e sociais, 'modos de ver' e relaciona-se com a esfera social da vida cotidiana, pois, a todo o momento somos interpelados por signos e significados criados pelas artes visuais.

Como campo "adisciplinar" e que se nutre de outras disciplinas (sociologia, filosofia, antropologia, psicologia, estudos sobre cinema, história da arte, estudos sobre cultura, etc.) a cultura visual é sem dúvida uma forte possibilidade para abordar estas e outras questões da atualidade, pois, de acordo com Fernando Hernández (2011), esta abordagem trata especialmente daquilo que nos cerca diariamente e que participa dos nossos processos de construção identitária.

Além disso, questiona as visões de mundo no que diz respeito às relações de poder. Poder entendido como "pensamento hegemônico, naturalização da realidade, grupos dominantes que se apropriam e que decidem como as coisas devem ser e como devemos 'ver', entender e nos comportar diante do mundo", e que, inevitavelmente, interferem na forma como agimos e nos construímos como sujeitos (HERNÁNDEZ, 2007). Como nos percursos rizomáticos sugeridos por Deleuze e Guattari (1995) que se ramificam estabelecendo conexões, mesclando-se e produzindo novas relações com o saber, podemos contribuir com o ato de questionar, fomentar a reflexão e o debate acerca das problemáticas contemporâneas em torno 
das imagens e suas representações vinculadas nos mais variados contextos culturais e sociais de produção e distribuição. Estas práticas nos oferecem a chance de revisitarmos nossas próprias crenças, valores e formas de compreender o mundo e nossas relações de aprendizagem.

Neste sentido, ao nos posicionarmos a partir de perspectivas que dialogam sob o enfoque da cultura visual, nos permitem criar contra discursos, transgredir ideias enraizadas, propor diferentes abordagens pois, como bem sabemos, existem infinitas alternativas de pensar e propor o tema da natureza-morta e não unicamente atrelado às heranças do positivismo histórico e hegemônico da arte.

\section{Considerações finais}

É importante pensarmos que todos os relatos e formas de narrar correspondem a invenções: foram criados e legitimados por pessoas a partir de critérios específicos. Ter em conta a natureza exploratória e interpretativa dos fatos históricos - sobretudo entorno aos artefatos culturais produzidos pelas distintas culturas - nos autoriza fugir da ideia de um único método que pode ser aplicado de forma estanque para estudar a história da arte: mas incita a pensar em "histórias das artes".

Aprendemos através do ato de estabelecer relações - o conhecimento não está em si mesmo, mas naquilo que é produzido a partir das conexões, dos diálogos estabelecidos (GERGEN, 1996). Portanto, enquanto os estudos da cultura visual se expandem, autores da crítica, teoria e história da arte contestam, configurando-se ameaça ao campo institucional da arte, justamente por tratar-se de um território de tensões e conflitos que ainda busca firmar-se como campo do conhecimento. Constitui-se, portanto, de várias histórias, atravessa questões interdisciplinares, ultrapassa os aspectos cronológicos como sucessão linear para pensar e propor caminhos mais alargados, onde as fronteiras sejam diluídas, oferecendo-nos espaço às múltiplas contestações (CHEREM, 2009).

Portanto, fundir categorias de uma história ocidental, clássica, normativa e linear, não só restringe nossas capacidades inventivas, como também pode negligenciar movimentos periféricos, culturas tidas como subalternas que durante 
muitos séculos foram subjugadas em detrimento de concepções eurocêntricas e/ou norte-americanas (anglo-saxônicas) de valores estéticos, filosóficos e morais acerca de verdade, realidade e representação.

A importância de justapor arte contemporânea em diálogo com produções modernas aqui pensadas não tem interesse em comparar ou contrastar ideais, mas estabelecer relações conectivas, compreender as maneiras com as quais podemos retomar nossas próprias ideias ao elaborar vias de conexão inventiva. Destarte, entendemos que os campos se expandem em relação ao que tem ao seu entorno e criam novos significados a partir das diversas imagens, sejam elas atuais ou deslocadas de determinados contextos históricos. De acordo com Cherem (2009) essas imagens perduram durante vários tempos, ultrapassam o fluxo regular das coisas e voltam para a contemporaneidade não de maneira idêntica, mas possíveis de articulação através de combinações e justaposições. Reverberando, portanto, conhecimentos e informações apreendidos de diversas maneiras, visto que as aprendizagens das gerações atuais acontecem através da articulação e cruzamento de informações e experiências vividas vinculadas às imagens, ideias, recursos e linguagens diversas.

\section{Referências}

CANTON, Kátia. Natureza-Morta. In. MUSEU DE ARTE CONTEMPORÂNEA/SESI. Natureza-morta: Still Life. São Paulo: MAC/USP, SESI, 2004.

CHEREM, Rosângela Miranda. Imagem - acontecimento. In: SILVA, Maria Cristina da Rosa Fonseca da; MAKOWIECKY ,Sandra (Orgs.). Linhas cruzadas: artes visuais em debate. Florianópolis: Ed. Da UDESC, 2009.

DELEUZE, Gilles; GUATTARI, Félix. Mil Platôs. Capitalismo e Esquizofrenia. v. 1. São Paulo: Editora 34, 1995.

DIAS, Belidson. O I/Mundo da Educação em Cultura Visual. Brasília: Editora da Pós-Graduação em Arte da Universidade de Brasília, 2011.

DUNCUM, Paul. Por que a arte-educação precisa mudar e o que podemos fazer. In: MARTINS, Raimundo e TOURINHO, Irene (Org.) Educação da Cultura Visual: conceitos e contextos. Santa Maria: EDUFSM, 2011. p. 15-30.

GALLEGUER, Ann (Org). Still Life Natureza-Morta. Londres: Art Library, 2002. Catálogo

GERGEN, Kenneth. Realidades y relaciones: aproximaciones a la construcción social. España: Paidós, 1996.

HERNANDEZ, Fernando. Catadores da Cultura Visual: Proposta para uma nova narrativa educacional. Porto Alegre: Mediação, 2007. 
KNAUSS, Paulo. Aproximações disciplinares: história, arte e imagem. Aproximações disciplinares: história, arte e imagem. Anos 90 - Revista do Programa de Pós-Graduação em História da UFRGS, Porto Alegre, v. 15, n. 18, p. 151-168, dez. 2008.

MITCHELL, W. J. T. What do pictures want?: the lives and loves of images. Chicago: Chicago University Press, 2005.

MOXEY, Keith. Nostalgia for the real: The troubled relation of the art history to visual studies. In The Practice of Persuasion: Paradoz and Power in Art History. Ithaca, N.Y.: Coronell University Press, 2001.

SCHNEIDER, Norbert. Naturezas-Mortas. Trad. Adelaide Cervaens Rodrigues e Teresa Carvalho. Lisboa: Taschen, 2009.

\section{Lutiere Dalla Valle}

Doutor em Artes Visuais e Educação (Universidad de Barcelona/ES), Mestre em Educación y Artes Visuales: un Enfoque Construccionista (Universidad de Barcelona/ES), Mestre em Educação pela Universidade Federal de Santa Maria (CE/PPGE/UFSM) linha de Pesquisa: Educação e Artes. Possui Especialização em Arte e Visualidade, Licenciatura Plena em Desenho e Plástica e Bacharelado em Desenho e Plástica pela mesma instituição. É professor adjunto no Departamento de Artes Visuais/CAL/UFSM do Programa de Pós-Graduação/PPGART - Linha de Pesquisa Arte e Cultura, e nos Cursos de Graduação Bacharelado e Licenciatura em Artes Visuais. Investiga as relações entre Artes Visuais e Cultura Visual relacionado à formação de artistas e professores, além de liderar Grupos de Pesquisa e Extensão na mesma área.

E-mail: lutiere@dallavalle.net.br

Currículo: http://lattes.cnpq.br/7210555983862366

\section{Milena Regina Duarte Corrêa}

Graduanda em Artes Visuais Licenciatura Plena pela Universidade Federal de Santa Maria. Atua como bolsista do Programa Institucional de Bolsa de Iniciação à Docência (PIBID/UFSM), bolsista do projeto de extensão: Art in Bag - Exposições Itinerantes (FIEX/UFSM). Membra do grupo de pesquisa: Artes Visuais e I/Mediações (AVI/CAL) e dos projetos de extensão: Núcleo Educativo Cláudio Carriconde (NECCA/CAL) e Arte Contemporânea e Educação da Cultura Visual: Pedagogias Culturais na Alfabetização Infantil. Tem interesse nas áreas de educação em Artes Visuais, cultura visual, história da arte e mediação de exposições em espaços formais e não formais de ensino.

E-mail: milenadc27@gmail.com

Currículo: http://lattes.cnpq.br/6761362028803725

Recebido em 13 de julho de 2017 Aceito em 30 de outubro de 2017 